\title{
Groundwater Quality in the Tahoe and Martis Basins, California
}

Groundwater provides more than 40 percent of California's drinking water. To protect this vital resource, the State of California created the Groundwater Ambient Monitoring and Assessment (GAMA) Program. The Priority Basin Project of the GAMA Program provides a comprehensive assessment of the State's groundwater quality and increases public access to groundwater-quality information. The Tahoe and Martis Basins and surrounding watersheds constitute one of the study units being evaluated.

\section{The Tahoe-Martis Study Unit}

The Tahoe-Martis study unit is approximately 460 square miles and includes the groundwater basins on the south, north, and west shores of Lake Tahoe, and the Martis Valley groundwater basin (California Department of Water Resources, 2003). The study unit was divided into three study areas based primarily on geography: the Tahoe study area composed of the three Tahoe Valley basins, the Martis study area, and the Hard Rock study area composed of the parts of the watersheds surrounding the basins (Fram and others, 2009).

The primary aquifers in the Tahoe study area consist of glacial outwash sediments (mixtures of sand, silt, clay, gravel, cobbles, and boulders), interbedded with lake sediments. The primary aquifers in the Martis study area are interbedded volcanic lavas, volcanic sediments, and glacial outwash sediments. In the Hard Rock study area, groundwater is present in fractured granitic rocks in the south and fractured volcanic rocks in the north. Aquifers composed of different materials commonly contain groundwater with different chemical compositions.

The primary aquifers in the study unit are defined as those parts of the aquifers corresponding to the screened or open intervals of wells listed in the California Department of Public Health database. In the Tahoe study area, these wells typically are drilled to depths between 175 and 375 feet, consist of solid casing from land surface to a depth of about 75 to 125 feet, and are screened or open below the solid casing. In the Martis study area, these wells typically are 200 to 900 feet deep, and are screened or open below 75 to 300 feet. Water quality in the shallower and deeper parts of the aquifer system may differ from that in the primary aquifers. The Hard Rock study area includes wells and developed springs.

The Tahoe-Martis study unit has warm, dry summers and cold, wet winters. Average annual precipitation ranges from 30 inches at Lake Tahoe to 80 inches in the surrounding mountains, and the majority of precipitation falls as snow. Land use in the study unit is approximately 88 percent (\%) undeveloped (forests, grasslands, and bare

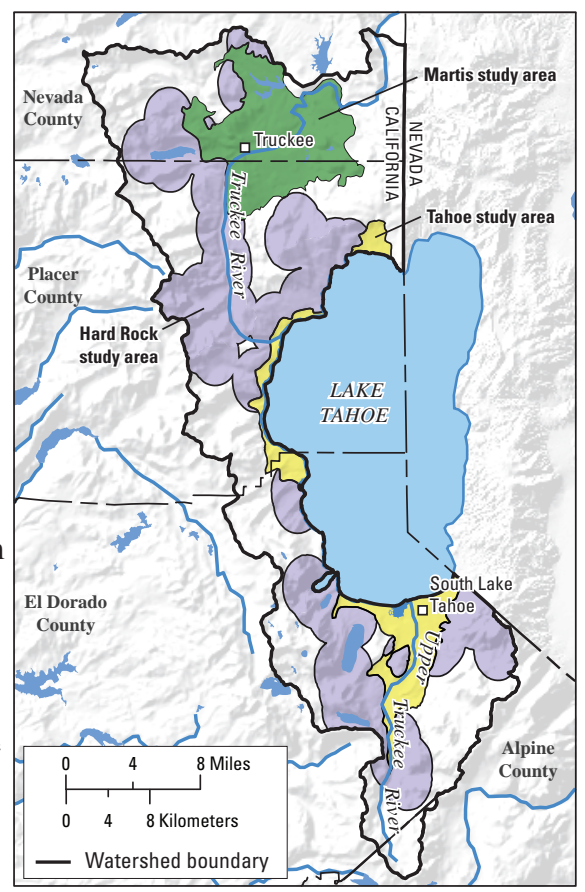

rock), and $12 \%$ urban. The undeveloped lands are used mostly for recreation. The largest urban areas are the cities of South Lake Tahoe and Truckee.

Municipal and community water supply accounts for nearly all of the total water use in the study unit, with most of the remainder used for recreation, including landscape irrigation and snow-making. Groundwater provides nearly all of the water supply in the study unit, with limited use of surface water in some areas. Recharge to the groundwater flow system is mainly from mountain-front recharge at the margins of the basins, stream-channel infiltration, and direct infiltration of precipitation. Groundwater leaves the aquifer system when it is pumped for water supply or flows into streams and lakes.

\section{Overview of Water Quality}

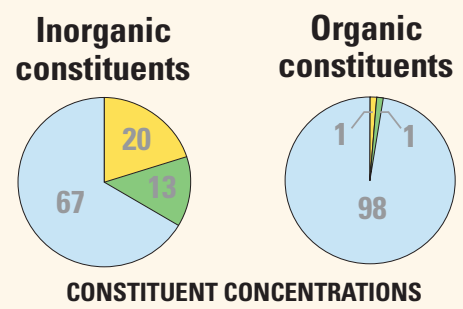

High Moderate $\bigcirc$ Low or not detected Values are a percentage of the area of the primary aquifers with concentrations in the three specified categories. Values on pie chart may not equal 100 due to rounding of percentages.

GAMA’s Priority Basin Project evaluates the quality of untreated groundwater. However, for context, benchmarks established for drinkingwater quality are used for comparison. Benchmarks and definitions of high, moderate, and low concentrations are discussed in the inset box on page 3 .

Many inorganic constituents occur naturally in groundwater. The concentrations of the inorganic constituents can be affected by natural processes as well as by human activities. In the TahoeMartis study unit, one or more inorganic constituents were present at high concentrations in about $20 \%$ of the primary aquifers and at moderate concentrations in $13 \%$.

Human-made organic constituents are found in products used in the home, business, industry, and agriculture. Organic constituents can enter the environment through normal usage, spills, or improper disposal. In this study unit, one or more organic constituents were present at high concentrations in about $1 \%$ of the primary aquifers and at moderate concentrations in about $1 \%$. 


\section{INORGANIC CONSTITUENTS}
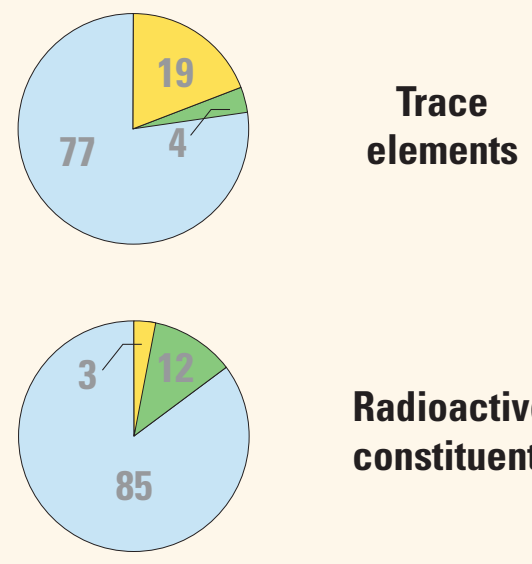

\section{Radioactive constituents}
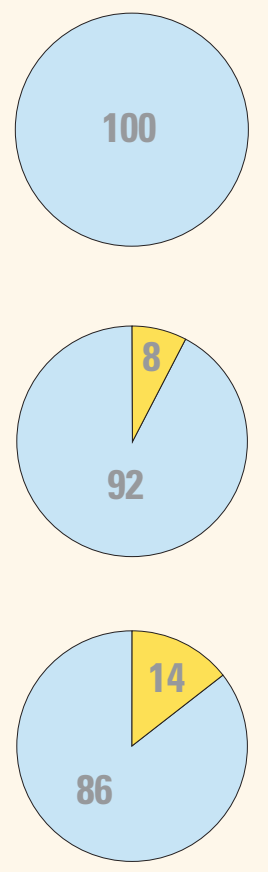

\section{Manganese}

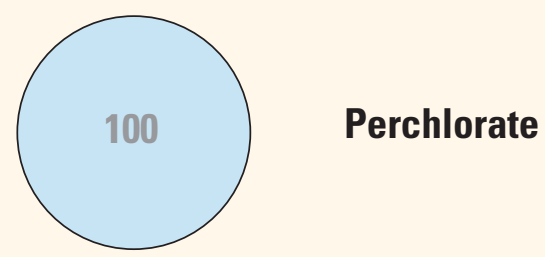

\section{Perchlorate}

(Not included in water-quality overview charts shown on the front page) Perchlorate is an inorganic constituent that has been regulated in California drinking water since 2007. It is an ingredient in rocket fuel, fireworks, safety flares, and other products, may be present in some fertilizers, and occurs naturally at low concentrations in groundwater. Perchlorate was not detected in the primary aquifers.

\section{Inorganic Constituents with Human-Health Benchmarks}

Trace and minor elements are naturally present in the minerals in rocks and soils, and in the water that comes into contact with those materials. In the TahoeMartis study unit, trace elements were present at high concentrations in about 19\% of the primary aquifers, and in moderate concentrations in about $4 \%$. Arsenic was the trace element that most frequently occurred at high and moderate concentramolybdenum, and strontium, also were detected at high concentrations.

Radioactivity is the emission of energy or particles during spontaneous decay of unstable atoms. Humans are exposed to small amounts of natural radioactivity every day. Most of the radioactivity in groundwater comes from decay of naturally occurring uranium and thorium in minerals in the rocks or sediments of the aquifers. Radioactive constituents occurred at high levels in about 3\% of the primary aquifers, and at moderate levels in about $12 \%$. Gross alpha particle and radon-222 activities were the radioactive constituents that most frequently occurred at high and moderate levels.

Nutrients, such as nitrogen, are naturally present at low concentrations in groundwater. High and moderate concentrations generally occur as a result of human activities. Common sources of nutrients include fertilizer applied to crops and landscaping, seepage from septic systems, and human and animal waste. In the Tahoe-Martis study unit, nutrients were not detected at high or moderate concentrations in the primary aquifers.

\section{Inorganic Constituents with Non-Health Benchmarks}

(Not included in water-quality overview charts shown on the front page)

Some constituents affect the aesthetic properties of water, such as taste, color, and odor, or may create nuisance problems, such as staining and scaling. The State of California has a recommended and an upper limit for total dissolved solids (TDS). All water naturally contains TDS as a result of the weathering and dissolution of minerals in soils and rocks. Iron and manganese are naturally occurring constituents that commonly occur together in groundwater. Anoxic conditions in groundwater (low amounts of dissolved oxygen) may result in release of manganese and iron from minerals into groundwater.

In the Tahoe-Martis study unit, TDS was present at high concentrations (greater than the upper limit) in about $8 \%$ of the primary aquifers, and at low concentrations (less than the recommended limit) in about $92 \%$ of the primary aquifers. Manganese, with or without iron, was present at high concentrations in about $14 \%$ of the primary aquifers. 


\section{ORGANIC CONSTITUENTS}

Solvents

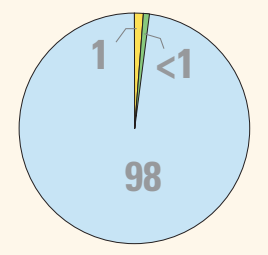

Other volatile organic compounds

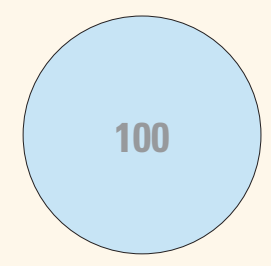

Pesticides

\section{Organic Constituents}

The Priority Basin Project uses laboratory methods that can detect the presence of low concentrations of volatile organic compounds (VOCs) and pesticides, far below human-health benchmarks. VOCs and pesticides detected at these low concentrations can be used to help trace water from the landscape into the aquifer system.

\section{Volatile Organic Compounds with Human-Health Benchmarks}

VOCs are in many household, commercial, industrial, and agricultural products, and are characterized by their tendency to volatilize (evaporate) into the air.

Solvents are used for a number of purposes, including manufacturing and cleaning. In the Tahoe-Martis study unit, solvents were present at high concentrations in about $1 \%$ of the primary aquifers. The solvent detected at high concentrations was tetrachloroethylene (PCE), which mainly was used in dry-cleaning businesses. Solvents were present at moderate concentrations in about $1 \%$ of the primary aquifers, and at low concentrations (or not detected) in about $98 \%$.

Other VOCs include trihalomethanes, gasoline additives and oxygenates, refrigerants, and organic synthesis reagents. Trihalomethanes form during disinfection of water supplies, and may enter groundwater by the infiltration of landscape irrigation water, or leakage from distribution lines. Gasoline additives and oxygenates increase the efficiency of fuel combustion. Other VOCs were not detected at high or moderate concentrations in the primary aquifers. Trihalomethanes and gasoline oxygenates were detected at low concentrations in the primary aquifers.

\section{Pesticides with Human-Health Benchmarks}

Pesticides, including herbicides, insecticides, fungicides, and fumigants, are applied to crops, gardens, lawns, around buildings, and along roads to help control unwanted vegetation (weeds), insects, fungi, and other pests. In the Tahoe-Martis study unit, pesticides were not detected at high or moderate concentrations in the primary aquifers. Herbicides were occasionally detected at low concentrations.

\section{BENCHMARKS FOR EVALUATING GROUNDWATER QUALITY}

GAMA’s Priority Basin Project uses benchmarks established for drinking water to provide context for evaluating the quality of untreated groundwater. After withdrawal, groundwater may be disinfected, filtered, mixed, and exposed to the atmosphere before being delivered to consumers. Federal and California regulatory benchmarks for protecting human health (Maximum Contaminant Level, MCL) were used when available. Nonregulatory benchmarks for protecting aesthetic properties, such as taste and odor (Secondary Maximum Contaminant Level, SMCL), and nonregulatory benchmarks for protecting human health (Notification Level, NL, and Lifetime Health Advisory, HAL) were used when Federal or California regulatory benchmarks were not available.

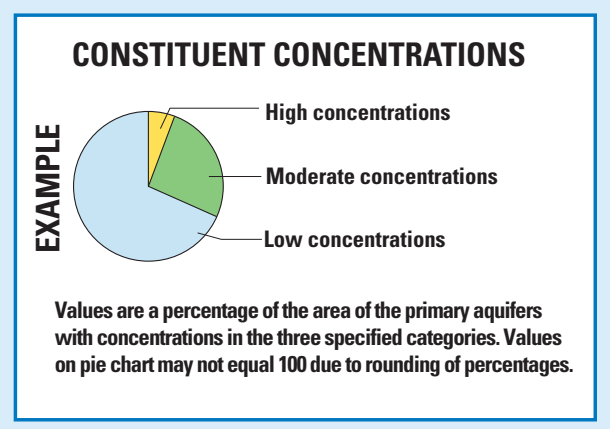

\section{High, moderate, and low concentrations are defined relative to benchmarks}

Concentrations are considered high if they are greater than a benchmark. For inorganic constituents, concentrations are moderate if they are greater than one-half of a benchmark. For organic constituents and perchlorate, concentrations are moderate if they are greater than one-tenth of a benchmark; this lower threshold was used because organic constituents are generally less prevalent and have smaller concentrations relative to benchmarks than inorganic constituents. Low values include nondetections and values less than moderate concentrations. Methods for evaluating water quality are discussed in Fram and Belitz (2012). 


\section{Factors that Affect Groundwater Quality}

In the Tahoe-Martis study unit, arsenic was the constituent that most frequently occurred at high concentrations. About $18 \%$ of the primary aquifers had arsenic concentrations greater than the human-health regulatory benchmark Federal MCL) of $10 \mu \mathrm{g} / \mathrm{L}$ (micrograms per liter). Natural sources of arsenic to groundwater include dissolution of arsenic-bearing sulfide minerals, desorption of arsenic from the surfaces of manganeseor iron-oxide minerals (or dissolution of those oxide minerals), and mixing with geothermal waters (Welch and others, 2000).

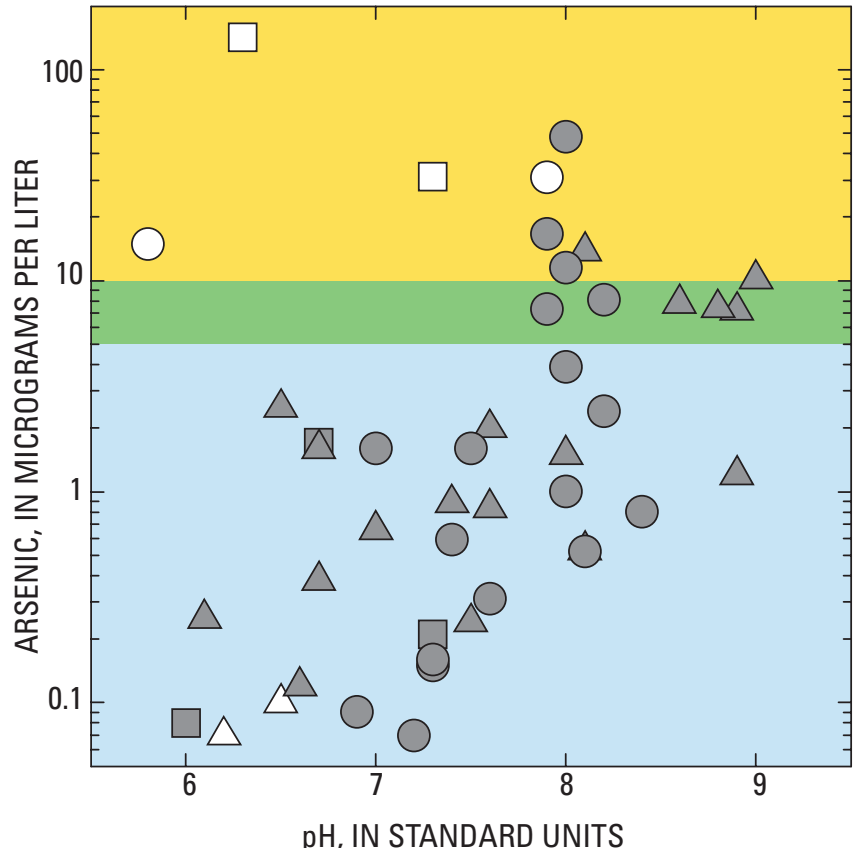

\section{EXPLANATION}

Aquifer rock type

granitic rock

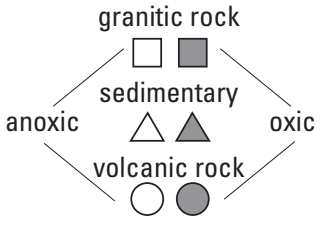

RelativeConcentration

High Moderate Low

In the Tahoe-Martis study unit, elevated arsenic concentrations likely are caused by two different processes (Fram and Belitz, 2012). In aquifers composed of sediments or volcanic rocks, high and moderate arsenic concentrations were found in groundwater that was oxic (high dissolved oxygen concentration) and alkaline ( $\mathrm{pH}$ values greater than about 8). The elevated arsenic concentration in oxic, alkaline groundwater likely is due to desorption of arsenic from the surfaces of manganese- and iron-oxide minerals (Smedley and Kinniburgh, 2002). Oxic, alkaline conditions increase arsenic solubility in groundwater by inhibiting arsenic from adhering to mineral surfaces (sorption). In aquifers composed of granitic and volcanic rocks, high arsenic concentrations also were found in anoxic (low dissolved oxygen concentration) groundwater with low $\mathrm{pH}$ values. Dissolution of manganese- and iron-oxide minerals under anoxic conditions likely results in release of arsenic associated with these minerals.

\section{By Miranda S. Fram and Kenneth Belitz}

\section{SELECTED REFERENCES}

California Department of Water Resources, 2003, California's groundwater: California Department of Water Resources Bulletin 118, 246 p. http://www.water.ca.gov/groundwater/bulletin118/update2003. $\underline{c f m}$.

Fram, M.S., Munday, Cathy, and Belitz, Kenneth, 2009, Groundwater quality data for the Tahoe-Martis study unit, 2007-Results from the California GAMA Program: U.S. Geological Survey Data Series 432, 87 p. (Also available at $h t t p: / / p u b s . u s g s . g o v / d s / 432 /$.

Fram, M.S., and Belitz, Kenneth, 2012, Status and understanding of groundwater quality in the TahoeMartis, Central Sierra, and Southern Sierra study units,2006-2007-California GAMA Program Priority Basin Project: U.S. Geological Survey Scientific Investigations Report 2011-5216, 222 p. (Also available at $\underline{h t t p: / / p u b s . u s g s . g o v / s i r / 2011 / 5216}$.)

Smedley, P.L., and Kinniburgh, D.G., 2002, A review of the source, behavior, and distribution of arsenic in natural waters: Applied Geochemistry, v. 17, p. 517-568.

Welch, A.H., Westjohn, D.B., Helsel, D.R., and Wanty, R.B., 2000, Arsenic in ground water of the United States—occurrence and geochemistry: Ground Water, v. 38, no. 4, p. 589-604.

\section{Priority Basin Assessments}

GAMA’s Priority Basin Project (PBP) assesses water quality in that part of the aquifer system used for drinking water, primarily public supply. Water quality in the primary aquifers, assessed by the PBP, may differ from that in the deeper parts of the aquifer, or from the shallower parts, which are being assessed by GAMA's Domestic Well Project. Ongoing assessments are being conducted in more than 120 basins throughout California.

The PBP assessments are based on a comparison of constituent concentrations in untreated groundwater with benchmarks established for protection of human health and for aesthetic concerns. The PBP does not evaluate the quality of drinking water delivered to consumers.

The PBP uses two scientific approaches for assessing groundwater quality. The first approach uses a network of wells to statistically assess the status of groundwater quality. The second approach combines waterquality, hydrologic, geographic, and other data to help assess the factors that affect water quality. In the TahoeMartis study unit, data were collected by the PBP in 2007, and from the CDPH database for 2004-2007. The PBP includes chemical analyses generally not available as part of regulatory compliance monitoring, including measurements at concentrations much lower than human-health benchmarks, and measurement of constituents that can be used to trace the sources and movement of groundwater.

\section{For more information}

Technical reports and hydrologic data collected for the GAMA PBP Program may be obtained from:

GAMA Project Chief

U.S. Geological Survey California Water Science Center 4165 Spruance Road, Suite 200

San Diego, CA 92101

Telephone number: (619) 225-6100

WEB: http://ca.water.usgs.gov/gama

GAMA Program Unit

State Water Resources Control Board Division of Water Quality

PO Box 2231, Sacramento, CA 95812

Telephone number: (916) 341-5779

WEB: http://www.waterboards.ca.gov/gama 